- Arif Novianto dan Anindya Dessi Wulansari

Universitas Gadjah Mada

\title{
Kerja Tak Terbayar di Media Sosial: Alienasi dan Eksploitasi Pekerja yang Tersamarkan dalam Kapitalisme Digital
}

\section{Pendahuluan}

Pengguna Internet di Indonesia pada tahun 2018 mencapai 132,7 juta jiwa di mana $98 \%$ nya menggunakan media sosial (Detik 2018). Sebagian besar dari mereka adalah generasi muda dan sering disebut sebagai prosumer, yaitu orang yang memproduksi (producers) dan mengkonsumsi (consumers) secara berbarengan dalam aktivitas digital.

Dalam dunia digital, berbagai kalangan menggunakan waktu luangnya (leisure time) untuk berselancar di media sosial seperti Facebook, Twitter, Instagram, atau Linkedin. Sebagai pengguna, di satu sisi mereka adalah pemproduksi konten di media sosial melalui upload status, foto, komentar, dan like. Di sisi lain mereka adalah konsumen karena disasar oleh berbagai iklan ketika melakukan aktivitas online. Para pengguna menjalankan aktivitas di media sosial tampak dengan suka cita seperti bermain-main tanpa mengetahui bahwa secara diam-diam data mereka dijual oleh korporasi media sosial menjadi iklan bertarget (Faucher 2018).

Proses komersialisasi informasi pengguna ini adalah bagian dari kapitalisme digital. Pengguna adalah konsumen produktif yang menghasilkan komoditas dan menciptakan keuntungan untuk korporasi media sosial (Fuchs 2014). Mereka sejatinya adalah pekerja dari korporasi media sosial yang termanifestasikan dari nilai lebih (surplus value) yang dihasilkan. Namun, curahan tenaga kerja para pengguna media sosial ini tidak dibayar. Mereka tidak menikmati hasil dari kerja yang dijual menjadi iklan oleh korporasi media sosial. Keadaan ini menunjukkan adanya eksploitasi dan alienasi (keterasingan).

Esai ini mengelaborasi tentang kerja yang sebenarnya dilakukan oleh pengguna media sosial namun tidak terbayar. Dalam esai ini peneliti berfokus pada media sosial Facebook. Dalam esai ini peneliti berfokus pada media sosial Facebook, untuk menjawab pertanyaan tentang apa yang dimaksud kerja dan nilai kerja dalam aktifitas media sosial? Bagaimana pengguna media sosial melakukan kerja di media sosial? Apa yang didapatkan Facebook dari para penggunanya? Bagaimana cara mereka melakukan akumulasi kapital? Apa implikasi dari model bisnis Facebook ini terhadap para penggunanya?

\section{Mendefinisikan Kerja, Kerja-bermain, dan Nilai Kerja}

Kerja menurut Karl Marx adalah hakikat dari kehidupan manusia. Melalui kerja, maka manusia dapat memanfaatkan dan merubah alam untuk memenuhi kehidupannya. Tanpa kerja, tidak akan ada keberlangsungan kehidupan bagi manusia (Engels 1876). Dalam bukunya German Ideology, Marx dan Engels (1845: 47) menyatakan bahwa kerja adalah kegiatan produktif yang dilakukan secara sadar untuk mentransformasikan dan mengorganisasikan alam sehingga manusia "memproduksi prasyarat bagi 
keberlangsungan hidupnya". Esensi utama kerja bagi manusia sejatinya begitu menyenangkan, karena selain untuk memenuhi kebutuhan hidup, juga untuk mengembangkan kapasitas diri dan untuk meluapkan energi agar bermanfaat (Fromm 2004). Kondisi itu dapat terjadi ketika tidak ada sistem sosial yang menjadikan aktivitas kerja dipenuhi rasa keterpaksaan dan membuat manusia terasing (alienasi).

Dalam masyarakat yang terbagi dalam kelas-kelas sosial, kerja memiliki watak lain yang telah menimbulkan alienasi dan eksploitasi. Di era kapitalisme sekarang, kerja eksploitatif dapat terus berlangsung karena keberadaan kelas sosial yang disebut "proletariat" (kelas pekerja) yang tidak memiliki sarana produksi, berbanding dengan segelintir kelas "borjuis" (kapitalis) yang memiliki sarana produksi. Tanpa memiliki sarana produksi, kelas pekerja hanya memiliki tenaganya saja untuk dapat bertahan hidup dengan cara menjual ke kelas kapitalis.

Kerja eksploitatif memiliki watak dialektis yang bertentangan dengan kapital (dimiliki oleh kapitalis). Menurut Marx, kerja yang berhadapan dengan kapital "adalah kerja yang terasing" dan kapital yang berhadapan dengan kerja "adalah kapital yang terasing" (Marx 1857/58: 266). Keberadaan kapital bergantung dengan aktifitas dari negasi kapital, yang bentuknya bukan-kapital, yaitu kerja. Watak dialektis yang bertentangan menjadikan hasil kerja dinikmati oleh kapitalis sebagai kekayaan, sementara menjadikan kemiskinan sebagai objek kerja. Sehingga Marx mencapai kesimpulan bahwa kapital sejatinya dibentuk dan diperbesar oleh kerja yang bersifat eksploitatif.

\section{Kerja-Bermain di Era Digital}

Dalam karyanya Gundrisse, Marx menjelaskan bahwa perkembangan kekuatan produksi dan ilmu pengetahuan akan menghasilkan kenaikan peran teknologi (ibid). Perkembangan teknologi ini dapat memicu kenaikan produktifitas dengan waktu pengerjaan yang semakin singkat, sehingga menurut Marx akan menciptakan banyak waktu luang bagi pekerja. Manusia akan memiliki keahlian dalam berbagai bidang dan banyak waktu sehingga dapat "berburu di pagi hari, memancing di siang hari, mengurus ternak di petang hari, melakukan kritik sesudah makan malam, persis seperti yang saya angankan, tanpa pernah menjadi pemburu, nelayan, gembala atau kritikus" (Marx dan Engels 1845/46: 53).

Ditemukannya internet pada akhir abad ke 20, telah membentuk relasi baru dalam kehidupan manusia. Media sosial mengemuka menghubungkan jutaan orang di gawai mereka masing-masing. Proses interaksi dengan begitu cepat menerobos ruang dan waktu. Media sosial secara umum digunakan ketika ada waktu senggang, sewaktu masyarakat telah selesai bekerja (dalam arti formal). Media sosial seperti arena bermain untuk berbagi informasi, memberi tombol suka, dan saling berkomentar. Manusia untuk bisa mengada tidak hanya harus makan, tetapi juga harus masuk ke dalam relasi sosial, berkomunikasi dan menjalin perkawanan. Isolasi seorang pribadi dari komunikasi dan jejaring sosial akan berakibat pada kematian atau keberadaan mirip hewan (Fuchs \& Sevignani 2018: 48). Media sosial memberi ruang untuk itu.

Relasi sosial terbentuk di media sosial seperti kegiatan bermain, namun pada hakikatnya mereka melakukan "kerja". Kondisi itu menjadi sesuatu yang jamak terjadi di era kapitalisme digital dan sering disebut sebagai kerja-bermain (playbour). Para pengguna di media sosial melakukan aktifitasnya seperti sukarela dengan berbagi pengalaman-pengalaman dan sikap mereka. Data tersebut ditampung oleh platform media sosial menjadi big data. Dengan data pengalaman dan 
preferensi personal itu, korporasi media sosial menjualnya untuk memfasilitasi kegiatan beriklan dengan tujuan akumulasi kapital. Hal tersebut juga dilakukan oleh media sosial Facebook yang menjadi fokus pembahasan esai ini. Kegiatan kerjabermain telah memberi limpahan data bagi korporasi media sosial tanpa mereka membayar para pekerja-bermain ini. Kita bisa membayangkan jika para pengguna Facebook, Twitter, Instagram, Wordpress, Wikipedia, dan juga yang lain tidak melakukan kerja-bermain, sudah pasti korporasi itu tidak akan memiliki apa-apa atau bangkrut.

\section{Facebook, Kapitalisme Digital dan Proses Akumulasi Kapital}

Melalui jargon di laman depan "Facebook membantu anda terhubung dan berbagi dengan orang-orang di kehidupan anda", membuat media sosial itu seolah menjadi instrumen penting bagi kehidupan bersosial karena memudahkan aksesbilitas networking di kalangan masyarakat. Jargon yang didukung berbagai konten ini telah sukses menarik minat banyak pengguna. Data tahun 2018 menunjukan pengguna harian Facebook adalah sebesar 2,17 miliar sebelumnya sebesar 1,2 miliar pengguna di tahun 2016 di seluruh dunia (Constine 2018), di mana lima yang teratas jumlah penggunanya adalah Indonesia. Jumlah pengguna yang mengalami lonjakan cukup besar ini, tidak terlepas dari strategi Facebook dalam membangun diskursus atau narasi kebaikan. Pengguna diarahkan perilakunya untuk meluangkan banyak waktu dan bermain-main lebih lama di Facebook tanpa menyadari bahwa ada yang salah dalam model bisnis Facebook. Tujuan keseluruhannya adalah untuk mencapai lebih banyak pengguna dan membuat pengguna menggunakan lebih banyak waktu pada Facebook sehingga proses

\footnotetext{
1 Transparansi digunakan untuk menjelaskan bahwa Facebook dapat menjawab pertanyaan "Mengapa saya melihat ini" dengan mengklik sebuah tombol yang disediakan pada tiap iklan. Kendali
}

akumulasi kapital dapat terus berjalan (Fuchs dan Sevignani 2018: 50).

Model bisnis Facebook dan platform media sosial lain dapat berjalan lancar dengan mendorong pengguna untuk memberikan data mereka, kemudian menggunakan data untuk tujuan komersial (Anthony \& Stark 2018). Ketika tomboltombol suka (like) dan share ditekan maka dengan begitu mereka terlibat dalam platform media sosial yang kemudian preferensinya diambil. Melalui preferensi itu, korporasi media sosial dapat menentukan iklan produk tertentu yang diminati oleh seorang pengguna profil facebook yang dinamakan sebagai teknik alogaritma.

Cara kerja pengambilan preferensi melalui alogaritma ini dilakukan facebook melalui tiga metode: Pertama, melalui informasi share dan like pengguna yang kemudian digunakan untuk mengetahui informasi personal pengguna dan kecenderungan preferensinya. Kedua, informasi tentang profil pengguna yang didapatkan melalui pengisian form informasi pendaftaran (sign up) dari calon pengguna (misalnya mengenai usia, gender, dan hobi) atau lokasi yang secara otomatis diketahui melalui penggunaan aplikasi Global Positioning System (GPS). Ketiga, melalui aktivitas pengguna pada situs web lain selain Facebook.

Berdasarkan kerangka kerja dari alogaritma, maka pengguna Facebook sebenarnya melakukan kerja yang berwujud data. Data berupa informasi dan preferensi personal di Facebook adalah hasil dari aktivitas online pengguna. Meskipun pihak Facebook berdalih tidak melakukan pencurian data dengan adanya poin transparansi dan kendali ${ }^{1}$, akan tetapi model bisnis Facebook tetap berjalan seperti biasanya. Aktivitas like, share,

yang dimaksudkan adalah menu pilihan yang diberikan facebook agar pengguna tidak lagi melihat iklan. 
informasi pribadi, dan aktivitas lain dari pengguna Facebook dalam hal ini merupakan bentuk dari kerja sosial para pengguna yang membuat Facebook tetap dapat hidup dengan adanya inovasi sesuai dengan preferensi pengguna. Inovasi dan ekspansi membuat pengguna terperangkap tiada henti oleh sistem yang digerakkan oleh akumulasi kapital.

Melalui penjualan data personal pengguna menjadi iklan, Facebook mengambil surplus nilai yang dihasilkan dari kerja pengguna menjadi kekayaan untuk korporasi media sosial itu. Model bisnis Facebook sangat bergantung pada iklan, karena sebagian besar pendapatan jaringan sosial berasal dari iklan. Pada 2017, sekitar 98 persen dari pendapatan global Facebook dihasilkan dari iklan. Pendapatan iklan Facebook mencapai lebih dari 39,9 miliar dolar AS pada tahun 2017, rekor baru untuk perusahaan dan peningkatan yang signifikan dibandingkan dengan tahun-tahun sebelumnya (Statista 2018). Itu merupakan pendapatan yang fantastis yang diperoleh dari Facebook dari kerja yang tidak dibayar kepada para pengguna Facebook. Kondisi itu menunjukan adanya alienasi dan eksploitasi yang dilakukan oleh Facebook terhadap para penggunanya.

Grafik 1: Pendapatan Iklan Facebook di seluruh dunia tahun 2009 - 2017

(dalam juta dolar AS)

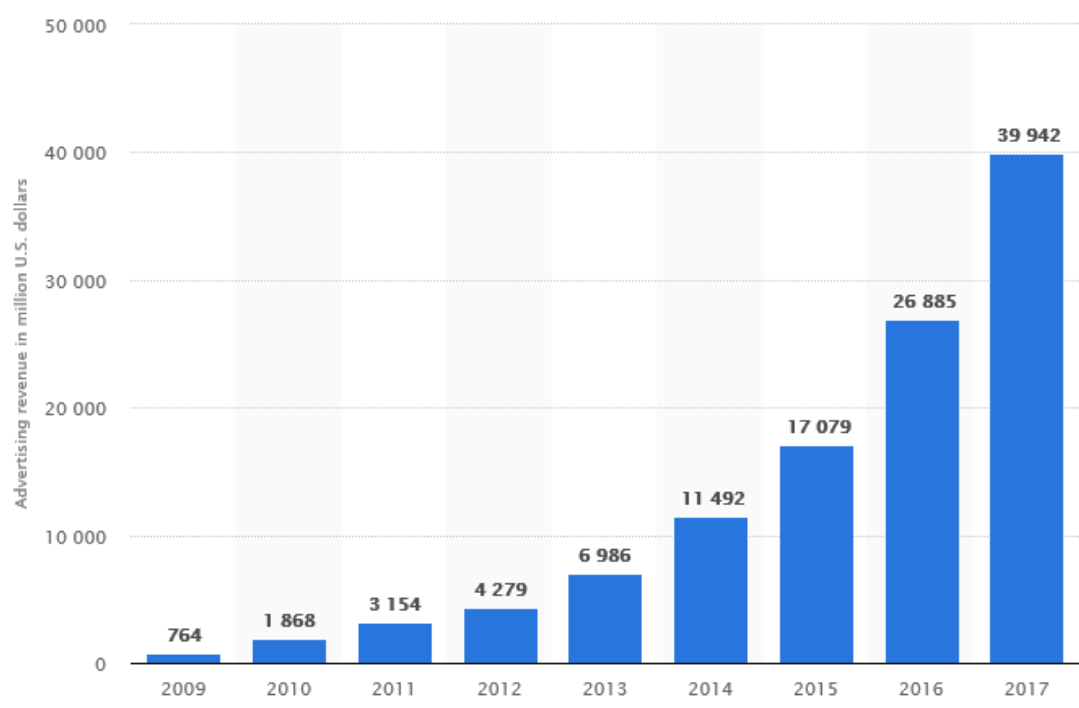

Sumber: Statista 2018

Facebook kini menjadi korporasi besar dengan miliaran pengguna yang menghabiskan waktu berjam-jam di sistem mereka untuk melakukan kerja tak terbayar. Investasi besar-besaran dilakukan oleh berbagai korporasi untuk beriklan ke Facebook agar konten atau komoditi mereka dapat terjual dengan menyasar pengguna Facebook. Saat ini Facebook dan Google menikmati posisi yang mirip monopoli dunia digital, yang mana diperkirakan $84 \%$ dari total iklan online yang dihabiskan pada 2017 masuk ke kedua perusahaan tersebut (Felle 2018).

\section{Keterasingan dan Eksploitasi Ter- samarkan dalam Facebook}

Para teoritisi kapitalisme digital telah berupaya menggali peran kerja nir-material di media sosial. Hardt dan Negri (2004: 108) merumuskan kerja nir-material sebagai kerja yang menghasilkan produk nir-material seperti komunikasi, informasi, pengetahuan, dan hubungan sosial. Sifatnya 
yang nir-material, memunculkan silang pendapat tentang keberadaan eksploitasi dan keterasingan dalam kerja-bermain di media sosial. Dalam "Alienation, Exploitation, and Social Media", P. J. Rey (2012) mempertanyakan konsep dasar Marxian dengan bertanya, dapatkah pengguna Facebook dianggap terasing dan atau dieksploitasi ketika mereka dengan senang hati memberikan tenaga kerja gratis ke situs web nirlaba?

Menurut Rey, pengguna tidak terasing di media sosial karena mereka tidak terputus dari konten yang mereka hasilkan dan bebas untuk membuat apa sesuai keinginannya. Di media sosial orang menjalankan aktivitasnya sesuai dengan keinginan dia sendiri, tidak ada peraturan yang mengatur, sehingga bermedia sosial menjadi pilihan bukan kewajiban. Bagi Rey itu berbeda dengan di Pabrik, ada SOP (Standart Operating Procedure) yang menjadi kewajiban pekerja dan jika tidak melakukannya maka akan mendapatkan sangsi hingga pemecatan.

Sementara menurut Cristian Fuchs dan Sebastian Sevignani (2018), aktivitas di media sosial telah mengalienasi manusia. Mereka melihat aktivitas di media sosial sebagai kerja produktif (kerja membuat komoditi) yang mengasingkan manusia dalam empat sisi: keterasingan dari diri sendiri, keterasingan dari objek kerja produtif (instrumen dan objek kerja produktif), dan keterasingan dari produk yang diciptakannya (2018: 48). Keterasingan empat sisi ini membentuk keterasingan dari seluruh proses produksi yang disebabkan oleh adanya relasi kelas dan menghasilkan eksploitasi. Proses produksi yang dimaksud adalah kegiatan produksi konten di media sosial yang menjadi data bagi korporasi media sosial seperti Facebook. Kepemilikan sarana produksi yang mengkondisikan kepengaturan terhadap semua kebijakan platform media sosial menjadikan korporasi media sosial mengklaim kepemilikan atas data pengguna. Sementara pihak pengguna media sosial tidak menikmati data hasil kerja mereka. Itu yang membuat mereka terasing dari hasil kerja yang dilakukan di media sosial, semetara mereka hanya mendapatkan nilai guna berupa informasi, relasi sosial, dan profil tertentu.

Media sosial pada perkembangannya telah menjadi ruang dan mekanisme untuk memperluas akumulasi kapital. Data tentang informasi dan preferensi personal dari kerja-bermain di Facebook contohnya, menjadi komoditi bagi korporasi media sosial untuk dijual ke korporasi lain dalam bentuk iklan. Kelebihan beriklan di Facebook, iklan dapat ditargetkan sesuai dengan data personal pengguna Facebook. Itu berbeda dengan beriklan di media umum seperti TV, Radio, Koran atau Reklame, iklan ditujukan ke semua orang atau ke demografi tertentu. Iklan itu tidak dapat ditujukan pada individu tertentu karena pengiklan dan media umum itu tidak memiliki informasi tentang pengguna tertentu dan tidak memiliki kapasitas untuk menjangkau mereka (Ritzer; dkk 2012: 388).

Data dan preferensi personal di Facebook (imaterial), menjadi komoditi yang spesifik mendorong upaya realisasi produksi terhadap barang material. Penargetan yang spesifik apalagi dengan algoritma, telah menjadi sumber keuntungan bagi korporasi Facebook. Modal akumulasi kapital dari Facebook berbasis pada pemasangan iklan yang terarah (Fuchs \& Sevignani 2018: 50). Isi dari iklan-iklan tersebut terutama berfokus pada mempromosikan barang-barang tertentu. Iklan-iklan Facebook mengarah pada membujuk pengguna untuk membeli barang-barang tertentu sesuai dengan target yang disasar. Keterasingan terjadi karena pengguna tidak mempunyai serta tidak dapat mengendalikan kebijakan Facebook dan mendapatkan hasil dari kerja mereka yang berupa data. 
Nilai di Facebook berarti waktu ratarata yang dihabiskan pengguna di platform. Hukum nilai di Facebook berarti bahwa semakin banyak waktu yang dihabiskan kelompok tertentu pada platform, semakin berharga komoditas data yang sesuai. Kelompok yang rata-rata menghabiskan banyak menit per hari di Facebook (misalnya kelompok pemuda yang berusia 15-25) dibandingkan dengan kelompok lain (misalnya kelompok yang berusia 75-85) merupakan komoditas data yang lebih berharga karena (a) ini memiliki rata-rata waktu kerja atau aktivitas online lebih tinggi per hari yang menghasilkan lebih banyak data yang dapat dijual, dan (b) menghabiskan lebih banyak waktu online, sehingga akan menjadi objek sasaran iklan (Fuchs 2014).

Akan tetapi pengasingan dan eksploitasi yang terjadi di Facebook bersifat tersamarkan sehingga membuat para pengguna seolah tidak merasa dirugikan. Eksploitasi ini tersamarkan karena terasa seperti tidak kerja keras, ini lebih seperti bermain dan berlangsung selama waktu senggang di luar aktivitas kerja atau kegiatan yang bersifat wajib. Para pengguna media sosial juga merasa aktivitas onlinenya sekadar untuk bersenang-senang, membangun relasi dengan orang lain, menunjukan informasi personal, atau sekedar mengisi waktu luang. Kondisi itu yang menyamarkan eksploitasi yang tengah terjadi.

Kerja yang tersamarkan berlangsung di era kapitalisme ini dan membuat aktivitas kerja terjadi sampai waktu luang atau senggang. Para kapitalis di era kapitalisme digital menjadi tidak hanya mencuri nilai lebih saat kerja formal berlangsung, tetapi juga mencuri nilai lebih dari aktivitas di waktu senggang. Rezim kapitalisme digital berupaya mendistorsi antara waktu senggang dan waktu kerja, dengan menjadikan semua itu menjadi waktu kerja. Itu karena di bawah kapitalisme, akumulasi kapital menjadi hal yang utama dan proses itu akan termaksimalisasi dengan cara menerobos ruang dan waktu.

\section{Kesimpulan}

Perkembangan teknologi telah memunculkan media sosial sebagai sarana aktualisasi diri bagi manusia. Mereka menggunakan media sosial seperti Facebook untuk saling berbagi, berkomunikasi, membentuk relasi, dan sarana kepuasan diri. Akan tetapi di rezim kapitalisme digital, aktivitas yang seperti bermain itu diubah menjadi kerja yang menghasilkan komoditi berupa data. Data itu oleh korporasi media sosial dijual menjadi iklan yang keuntungannya dinikmati oleh korporasi itu sendiri.

Aktivitas di media sosial menjadi terkomersialkan karena kepentingan ekonomi dari pemilik sarana produksi platform media sosial. Mereka yang mengontrol dan mengendalikan data dari konten-konten dan aktivitas pengguna media sosial. Sementara para pengguna terasingkan, karena tidak bisa menikmati hasil kerja berupa data dari pengalaman mereka. Watak dialektis kerja yang bersifat ganda terjadi dalam kapitalisme digital media sosial ini. Kerja para pengguna menjadi kekayaan bagi pemilik kapital media sosial dan menjadi kemiskinan bagi pengguna akibat kerja mereka tidak terbayarkan.

Eksploitasi terjadi di Facebook dengan watak ganda. Pertama, eksploitasi karena nilai kerja pengguna hanya dinikmati oleh korporasi Facebook, sedangkan waktu kerja mereka tidak dibayar oleh Facebook. Kedua, eksploitasi terjadi karena pengguna yang sejatinya adalah pemproduksi data justru disasar sebagai obyek iklan dan konsumen untuk komoditi lain melalui piranti Facebook. Akan tetapi para pengguna tidak merasa dirugikan karena eksploitasi terjadi secara tersamarkan. 
Para pengguna Facebook dan media sosial lain sejatinya adalah subjek yang membangun platform media sosial itu dari kerja yang mereka lakukan. Korporasi media sosial berhutang dan berkewajiban untuk memenuhi nilai kerja para pengguna yang telah menjadi sumber keuntungan mereka. Jika para pengguna berhenti melakukan aktivitas onlinenya atau mogok, maka sudah dapat dipastikan korporasi media sosial akan luluh lantak (bangkrut). Itu menunjukkan bahwa para pengguna sebenarnya adalah produsen sekaligus konsumen.

Itu berbeda jika kepemilikan media sosial adalah kepemilikan bersama secara komunal, bukan kepemilikan privat. Keterasingan dan eksploitasi menjadi tidak terjadi selama aktivitas bermedia sosial tidak dijadikan sebagai komoditi.

\section{Referensi}

Anthony, Denise \& Luke Stark. 2018. "Jangan Berhenti Pakai Facebook tapi Jangan Mempercayainya". (https://theconversation.com/janganberhenti-pakai-facebook-tapijangan-mempercayainya-juga94506). Diakses Pada 16 Oktober 2018. Pukul 15.00 WIB

Constine, Josh. 2018. "Facebook Stock Tanks From mix Q2 With Slowest Ever Growth". Diakses Pada 16 October 2018, 02.55 PM. Accesed from

(https://techcrunch.com/2018/07/25/ facebook-q2-2018-earnings/)

Detik (Online). 12 Maret 2018. "130 Juta Orang Indonesia Tercatat Aktid di Medsos". (https://inet.detik.com/cyberlife/d3912429/130-juta-orang-indonesiatercatat-aktif-di-medsos)

Engels, Frederick. 1876 (1934). The Part played by Labour in the Transition from Ape to Man. Moscow: Progress Publishers.

Faucher, K. X. 2018. Social Capital Online: Alienation and Accumulation. London: University of Westminster Press.

Faucher, Kane X. 2018. "Perburuan Sia-sia Mendapatkan Likes di Media Sosial". (https://theconversation.com/perburu an-sia-sia-mendapatkan-likes-dimedia-sosial-102575). Diakses Pada 16 Oktober 2018. Pukul 15.00 WIB

Felle, Tom. 2018. "Facebook mengurangi berita agar Anda menghabiskan waktu lebih banyak melihat iklan". (https://theconversation.com/faceboo k-mengurangi-berita-agar-andamenghabiskan-waktu-lebih-banyakmelihat-iklan-91427), diakses pada 17 Oktober 2018.

Fromm, Erich. 2004. Marx's Concept of Marx. London \& New York: Bloomsbury Academic.

Fuchs, Christian \& Sevignani, Sebastian. 2018. Mengenal Perbedaan Kerjateralienasi Digital (Digital Labour) dan Kerja-Umum Digital (Digital Work). -: Indoprogress.

Fuchs, Christian. 2014. Digital Labour and Karl Marx. London: Routledge.

Fuchs, Christian. 2014b. "Digital Prosumption Labour on Social Media in the Context of the Capitalist Regime of Time". Time \& Society, 2014, Vol. 23(1) 97-123.

Hardt, Michael and Antonio Negri. 2004. Multitude. New York: Penguin.

Johnson, Eric, Steven Bellman, \& Gerald L. Lohse. 2002. "Defaults, Framing and Privacy: Why Opting In-Opting Out". Journal of Marketing Letters, Vol 13, pp 5-15. Published by Kluwer Academic: Netherlands 
Marx, Karl and Friedrich Engels. 1845/46.

The German Ideology. New York: Prometheus Books.

Marx, Karl. 1857/58b. Grundrisse. London: Penguin.

Rey, P. J. 2012. Alienation, exploitation, and social media. American Behavioral Scientist, 56(4), 399-420.

Statista(dot)com. 2018. "Facebook's Advertising Revenue Worldwide from 2009 to 2017 (in million U.S. dollars)". Sumber: (https://www.statista.com/statistics/2 71258/facebooks-advertisingrevenue-worldwide/), diakses pada 17 Oktober 2018.

Toffler, A. (1980). The third wave. New York, NY: William Morrow 